\title{
Nonequilibrium Ablation of Phenolic Impregnated Carbon Ablator
}

\author{
F. S. Milos* and Y.-K. Chen \\ NASA Ames Research Center, Moffett Field, California 94035-1000 \\ and \\ T. Gökçen \\ ELORET Corporation, Sunnyvale, California 94086 \\ DOI: $10.2514 / 1 . A 32298$
}

\begin{abstract}
In previous work, an equilibrium ablation and thermal response model for Phenolic Impregnated Carbon Ablator was developed. In general, over a wide range of test conditions, model predictions compared well with arcjet data for surface recession, surface temperature, in-depth temperature at multiple thermocouples, and char depth. In this work, additional arcjet tests were conducted at stagnation conditions down to $40 \mathrm{~W} / \mathrm{cm}^{2}$ and $1.6 \mathrm{kPa}$. The new data suggest that nonequilibrium effects become important for ablation predictions at heat flux or pressure below about $80 \mathrm{~W} / \mathrm{cm}^{2}$ or $10 \mathrm{kPa}$, respectively. Modifications to the ablation model to account for nonequilibrium effects are investigated. Predictions of the equilibrium and nonequilibrium models are compared with the arcjet data.
\end{abstract}

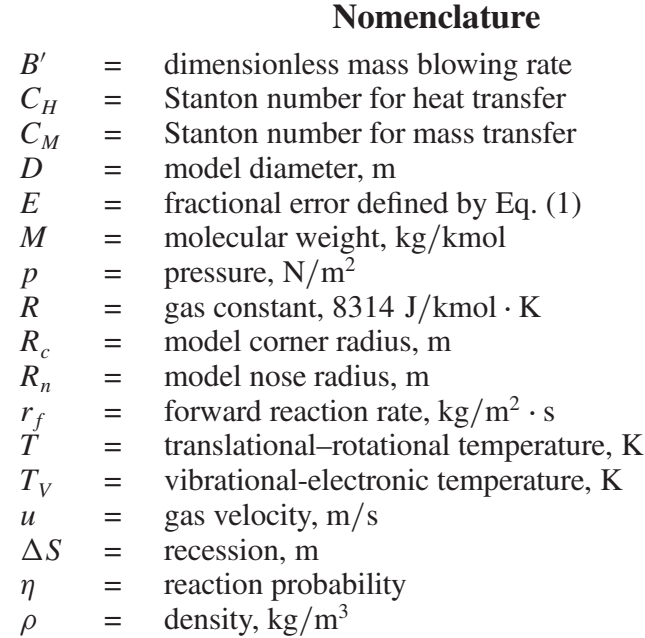

Subscripts

$c \quad=$ char or carbon

$e \quad=$ boundary-layer edge

$g \quad=$ pyrolysis gas

$o \quad=$ oxygen

$(s)=$ solid phase

\section{Introduction}

$\mathbf{P}$ HENOLIC impregnated Carbon Ablator (PICA) is a lowdensity composite material made from a rigid, carbon fiber insulation impregnated with a phenolic resin [1]. PICA was the heat shield material on the Stardust sample-return capsule [2], which is to

Presented as Paper 2010-0981 at the 48th AIAA Aerospace Sciences Meeting, Orlando, FL, 4-7 January 2010; received 22 December 2011; revision received 12 March 2012; accepted for publication 2 May 2012. This material is declared a work of the U.S. Government and is not subject to copyright protection in the United States. Copies of this paper may be made for personal or internal use, on condition that the copier pay the $\$ 10.00$ percopy fee to the Copyright Clearance Center, Inc., 222 Rosewood Drive, Danvers, MA 01923; include the code 0022-4650/12 and $\$ 10.00$ in correspondence with the CCC.

*Aerospace Engineer, Thermal Protection Materials Branch, Mail Stop 234-1. Senior Member AIAA.

Aerospace Engineer, Thermal Protection Materials Branch, Mail Stop 234-1. Member AIAA.

+Currently Senior Research Scientist, ERC, Inc., Mail Stop 230-2. Associate Fellow AIAA. date the fastest man-made Earth-entry vehicle. PICA also is the heat shield material for the Mars Science Laboratory (MSL) [3], and it was one of two candidate materials for the Orion Crew Module [4]. A similar material, named PICA-X, is manufactured by SpaceX for the Dragon spacecraft $\underline{\underline{s}}$.

The Orion thermal protection system (TPS) Advanced Development Project conducted extensive thermal, mechanical, and other material property testing of PICA. Based on test results, the PICAv3.3 material property modelI was developed specifically for use with the fully implicit ablation and thermal-response (FIAT) code that calculates ablation, pyrolysis, and thermal conduction in one dimension [5]. This code and the PICAv3.3 model have been used for analysis of ground tests as well as for thermal analysis and sizing of PICA tiles for flight applications on Orion, MSL, and Dragon.

A large number of stagnation arcjet tests were performed to acquire data on PICA thermal and ablative performance over a wide range of aerothermal conditions applicable to Orion low-Earth-orbit and lunar-return entries. The PICAv3.3 model was validated by comparison of numerical predictions with this large database of stagnation arcjet test data [6]. In general, the comparisons showed an excellent agreement between predictions and data for total recession, surface temperature, in-depth temperature at multiple thermocouples, and char depth. The error in recession predictions was less than $10 \%$ except for a few tests conducted at low heat flux or low pressure.

In [6], it was suggested that modifications to the modeling to account for nonequilibrium flowfield and ablation effects might improve the predictions at low test conditions. Since the development of the PICAv3.3 model, the MSL and Orion projects conducted additional stagnation arcjet tests of PICA including some environments with low heat flux or pressure. The purpose of this work is to describe modifications to the ablation model that account for nonequilibrium effects and to compare the model predictions with the arcjet data.

\section{Arcjet Models, Data, and Test Conditions}

PICA arcjet models were exposed to 15 test conditions that are plotted in Fig. 1 and listed in Table 1 in order of increasing heat flux. Four conditions, shown as triangles, were analyzed previously [6]. The circles are new test conditions. Based on previous experience with the arcjet facilities, the uncertainty of the stagnation pressure is considered to be less than $\pm 5 \%$, whereas the uncertainty in

\footnotetext{
${ }^{\S}$ SpaceX press release available at http://www.spacex.com/press.php? page $=20090223$ [retrieved 7 Aug. 2012].

"Milos, F. S., and Chen, Y.-K., "Ablation and Thermal Property Model for Phenolic Impregnated Carbon Ablator (PICA)," NASA-TM-2009-215377, March 2009.
} 


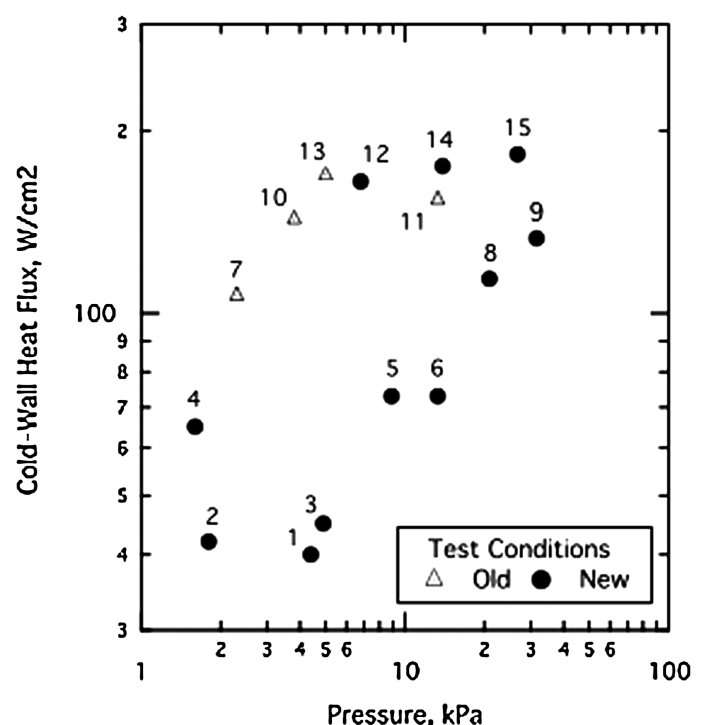

Fig. 1 Measured stagnation pressure and cold-wall heat flux for test conditions in Table $\underline{1}$.

stagnation heat flux is at least $\pm 10 \%$. The tabulated values are the average measurement obtained from all runs at a given test condition.

All tests were conducted in the Aerodynamic Heating Facility (AHF) at NASA Ames Research Center (ARC) [7]. For each test condition, multiple runs and/or multiple swing arms were used to obtain calibration measurements of stagnation pressure and coldwall heat flux. For most runs, these quantities were measured using a combination slug-calorimeter/pitot-pressure device (Fig. 2) that had the same external shape as the TPS samples to be tested [8] $]$. For this iso- $q$ shape, the nose radius equals the diameter, the corner radius is $1 / 16$ of the diameter, and the sides are cylindrical. The primary advantage of the iso-q geometry, compared with a flat-faced geometry, is that, in the ARC arcjets, the heat flux distribution is relatively constant over most of the front face of the iso-q shape. All PICA models were manufactured with the lower conductivity direction parallel to the axis of symmetry. Twenty-nine models had a 10.16-cm-diam iso-q shape. For environment 2 only, the two models had a $12.7-\mathrm{cm}$-diam flat-faced shape, and a flat-faced calorimeter was used to measure the stagnation conditions.

In the ARC facilities, argon is used to protect the upstream electrode, the main air is added along the length of the arcjet column, and finally additional air (called "add air") may be injected after the downstream electrode. The purpose of add air is to increase the pressure. In the AHF, there is a mixing chamber for add air between the downstream electrode and the nozzle. The argon mass fraction in Table 1 was calculated by assuming that the three streams become thoroughly mixed, and noting that dry air contains about $1.3 \%$ argon by mass. The argon mass fraction varied from $8.6 \%$ to $27.6 \%$. Argon is unreactive to TPS materials, and the primary effect of argon addition is simply to reduce by dilution the oxygen concentration in the flowfield. Because the ablation rate of carbon is a strong function of the oxygen concentration, it is important to include the argon mass fraction in the ablation calculations. In this work, ablation tables for each air/argon mixture were calculated using the Multicomponent Ablation Thermochemistry (MAT) code [9].

Table 2 provides a list of the models tested, the exposure time, the measured centerline recession, and the maximum surface temperature. The tabulated maximum temperature is the mean of the values obtained from multiple pyrometers after all corrections. Based on previous experience [6] , the uncertainty of the centerline recession and the maximum surface temperature are considered to be $\pm 0.5 \mathrm{~mm}$ and $\pm 5 \%$, respectively.

\section{Flowfield Analyses}

The Data Parallel Line Relaxation (DPLR) code [10] is used for computations of the nonequilibrium flow in the nozzle and around the calorimeter or TPS model. DPLR has been used extensively at ARC for hypersonic flight and planetary entry simulations, and its results have been compared against a wide variety of flight and ground-based experiments. In this work, the steady, axisymmetric Navier-Stokes equations are supplemented with equations for nonequilibrium kinetic processes. The thermochemical model includes six species $\left(\mathrm{N}_{2}, \mathrm{O}_{2}, \mathrm{NO}, \mathrm{N}, \mathrm{O}, \mathrm{Ar}\right)$. The thermal state of the gas is described by Park's two-temperature model $[11,12]$ with translational-rotational temperature $T$ and vibrational-electronic temperature $T_{V}$.

The flowfield in an arcjet facility, from the arc heater to the test section, is a complex, three-dimensional flow coupled to various nonequilibrium processes. To simulate the flowfield, several simplifying assumptions are made, and corresponding numerical boundary conditions are prescribed for the simulation. The DPLR simulations are started from the nozzle throat, where the flow properties are assumed to be in thermochemical equilibrium. At the model surface, the boundary condition is a fully catalytic cold wall, corresponding to flow around a copper calorimeter. The total enthalpy level and distribution at the nozzle throat are set such that the computations reproduce the facility and calibration data as well as possible. The facility data include measurements of total pressure (arc-heater pressure), mass flow rate, total bulk enthalpy, and test box pressure, whereas the calibration data include stagnation-point calorimeter heat flux and pitot pressure. Further details of the assumptions and numerical boundary conditions are provided in [13].

$\overline{\mathrm{As}}$ an illustration of a typical simulation, Fig. 3 shows computed Mach contours of the AHF $45.7 \mathrm{~cm}$ conical nozzle flow with an

Table 1 Stagnation arcjet test conditions

\begin{tabular}{|c|c|c|c|c|c|c|c|c|c|}
\hline $\begin{array}{l}\text { Test } \\
\text { condition }\end{array}$ & Project & $\begin{array}{l}\text { Stagnation cold-wall } \\
\text { heat flux, } \mathrm{W} / \mathrm{cm}^{2}\end{array}$ & $\begin{array}{l}\text { Stagnation } \\
\text { pressure, } \mathrm{kPa}\end{array}$ & $\begin{array}{l}\text { Centerline enthalpy } \\
\text { DPLR, MJ } / \mathrm{kg}\end{array}$ & $\begin{array}{l}\text { Main air, } \\
\mathrm{g} / \mathrm{s}\end{array}$ & $\begin{array}{c}\text { Add air, } \\
\mathrm{g} / \mathrm{s}\end{array}$ & $\begin{array}{l}\text { Argon, } \\
\text { g/s }\end{array}$ & $\begin{array}{l}\text { Argon mass } \\
\text { fraction }\end{array}$ & $\begin{array}{c}\text { Exposure } \\
\text { time, } s\end{array}$ \\
\hline 1 & Orion & 40 & 4.4 & 5.2 & 110 & 180 & 34 & 0.1166 & 200 \\
\hline $2 \mathrm{a}$ & Orion & 42 & 1.8 & 11.4 & 80 & 30 & 29 & 0.2189 & 200 \\
\hline 3 & MSL & 45 & 4.9 & 5.6 & 120 & 200 & 35 & 0.1103 & 240 \\
\hline 4 & Orion & 65 & 1.6 & 11.4 & 80 & 30 & 29 & 0.2189 & 200 \\
\hline 5 & MSL & 73 & 8.9 & 6.4 & 220 & 330 & 44 & 0.0861 & 120 \\
\hline 6 & Orion & 73 & 13.3 & 4.6 & 60 & 100 & 29 & 0.1644 & 120 \\
\hline 7 & Orion & 107 & 2.3 & 15.2 & 80 & 0 & 29 & 0.2756 & 55 \\
\hline 8 & MSL & 114 & 20.9 & 5.9 & 80 & 170 & 32 & 0.1250 & 80 \\
\hline 9 & MSL & 133 & 31.6 & 6.1 & 110 & 290 & 38 & 0.0986 & 80 \\
\hline 10 & Orion & 143 & 3.8 & 16.5 & 150 & 0 & 29 & 0.1729 & 200,400 \\
\hline 11 & Orion & 154 & 13.3 & 8.6 & 80 & 50 & 29 & 0.1930 & 33,66 \\
\hline 12 & MSL & 165 & 6.8 & 14.3 & 260 & 30 & 34 & 0.1166 & 50 \\
\hline 13 & Orion & 169 & 5.0 & 17.0 & 200 & 0 & 30 & 0.1417 & 33,60 \\
\hline 14 & MSL & 175 & 13.9 & 9.4 & 80 & 50 & 29 & 0.1930 & 50 \\
\hline 15 & MSL & 183 & 26.7 & 8.6 & 128 & 160 & 34 & 0.1172 & 50 \\
\hline
\end{tabular}

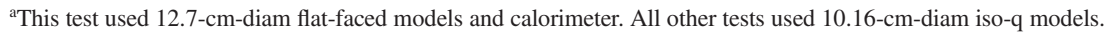




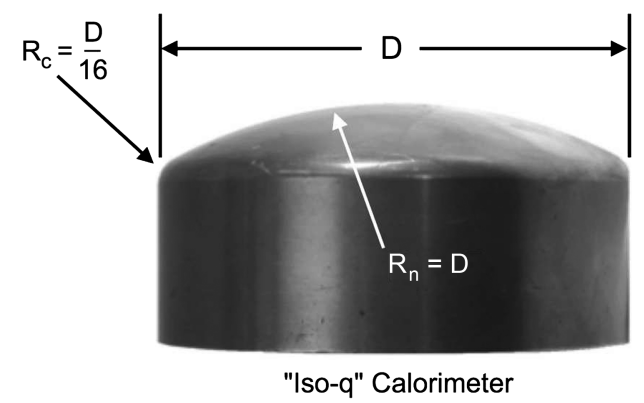

Fig. 2 Calorimeter and model shape for stagnation arcjet tests.

iso-q-shaped calorimeter placed $30.48 \mathrm{~cm}$ downstream of the nozzle exit. The solution is for test condition 1 of Table 1 . The computed Mach number is approximately 8 at the bow shock in front of the calorimeter. The computed temperatures along the stagnation streamline are plotted in Fig. 4. The translational-rotational temperature increases greatly across the shock, but the vibrational temperature does not rise as quickly. However, the flow approaches thermal equilibrium near the boundary-layer edge, defined herein as the location where the total enthalpy is $99.5 \%$ of the freestream value. Table 3 lists the temperatures and species mass fractions, at the estimated location of the boundary-layer edge, for each test condition. For comparison purposes, the Chemical Equilibrium with Applications (CEA) code [14] was used to estimate the equilibrium species mass fractions at the pressure and temperature calculated by DPLR at the boundary-layer edge location. These quantities are provided in Table 4.

Figures $\underline{5}-\mathbf{7}$ provide representative examples of species mass fraction profiles on the stagnation streamline. These profiles show three types of behavior, depending mostly on the value of the centerline enthalpy. Test conditions 1,3 , and 6 have the lowest enthalpy $(<5.7 \mathrm{MJ} / \mathrm{kg})$. There is no evidence of significant chemical reactions in the shock layer (Fig. 5). The species profiles are flat

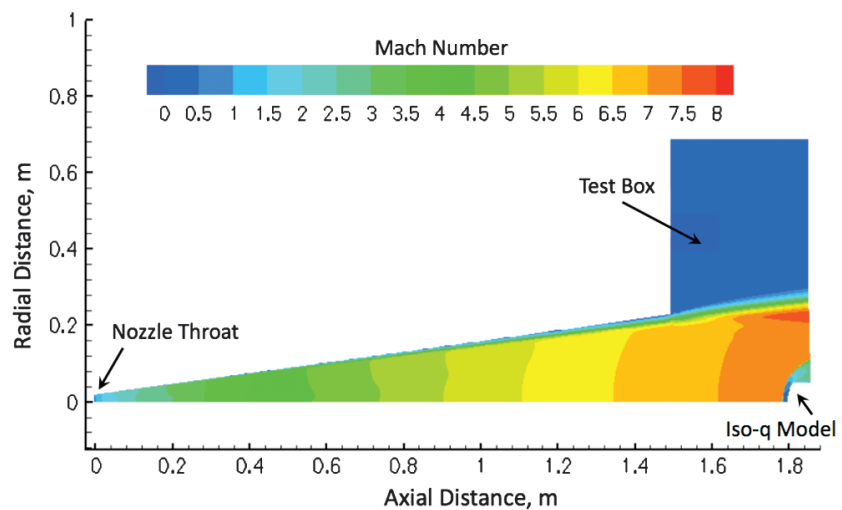

Fig. 3 Computed Mach number contours for test condition 1.

except for the boundary layer near the surface. The fully catalytic boundary condition forces the complete conversion of $\mathrm{O}$ to $\mathrm{O}_{2}$ at the wall. At the boundary-layer edge, the species are not in chemical equilibrium; specifically, there is a large excess of $\mathrm{O}_{2}$ and a deficiency of $\mathrm{O}$. Nitric oxide (NO) also is significantly above the equilibrium value.

Test conditions 5, 8, and 9 have intermediate levels of enthalpy (5.9-6.4 MJ/kg). Results for these conditions are similar to the preceding, except that some chemical reactions occur in the shock layer (Fig. 6). $\mathrm{O}_{2}$ is greater than $\mathrm{O}$, and there is some conversion of $\mathrm{N}_{2}$ and $\mathrm{O}_{2}$ to $\overline{\mathrm{O}}$ and $\mathrm{NO}$. Atomic oxygen is far below equilibrium value. NO is above the equilibrium value, but nevertheless increases as the flow approaches the boundary-layer edge.

Test conditions 2, 4, 7, and 10-15 have the highest enthalpy $(>8.5 \mathrm{MJ} / \mathrm{kg})$. Clearly, reactions are occurring in the shock layer (Fig. 7). Molecular oxygen is almost fully dissociated at the shock. The atomic oxygen is slightly below the equilibrium value because some oxygen is incorporated into NO. The relative amounts of $\mathrm{N}$, $\mathrm{NO}$, and $\mathrm{O}$ vary on a case-to-case basis (see Table $\underline{3}$ ).

Table 2 Measured quantities for arcjet models

\begin{tabular}{|c|c|c|c|c|}
\hline Test condition & Exposure time, s & Model ID & Centerline recession, $\mathrm{mm}$ & Maximum surface temperature, $\mathrm{K}$ \\
\hline 1 & 200 & OT-NG-3 & 6.33 & 1559 \\
\hline 1 & 200 & AA-44-234-N & 6.51 & 1560 \\
\hline 2 & 200 & AHF277-5-001 & 3.63 & 1651 \\
\hline 2 & 200 & AHF277-5-002 & 3.83 & 1652 \\
\hline 3 & 240 & Iso-03 & 9.45 & 1605 \\
\hline 4 & 200 & 17 & 6.90 & 1763 \\
\hline 4 & 200 & AA-44-237-N & 7.01 & 1767 \\
\hline 5 & 120 & Iso-06 & 7.39 & 1765 \\
\hline 5 & 120 & Iso-07 & 7.37 & 1762 \\
\hline 6 & 120 & OT-NG-4 & 8.71 & 1848 \\
\hline 6 & 120 & AA-44-236-N & 8.51 & 1839 \\
\hline 7 & 55 & AA-43-209-N & 2.33 & 2023 \\
\hline 7 & 55 & AA- $43-210-N$ & 2.27 & 2035 \\
\hline 8 & 80 & Iso-14 & 8.99 & 1948 \\
\hline 8 & 80 & Iso-15 & 8.38 & 1935 \\
\hline 9 & 80 & Iso-16 & 10.08 & 1944 \\
\hline 9 & 80 & Iso-17 & 10.06 & 1940 \\
\hline $10 \mathrm{a}^{\mathrm{a}}$ & 200 & AT-008 & 12.66 & 2170 \\
\hline $10 \mathrm{~b}=$ & 400 & AT-007 & 24.72 & 2188 \\
\hline $11 \mathrm{a}$ & 33 & AA-44-210-N & 2.93 & 2123 \\
\hline $11 \mathrm{a}$ & 33 & AA-44-211-N & 2.92 & 2116 \\
\hline $11 \mathrm{~b}$ & 66 & AA-44-212-N & 5.61 & 2116 \\
\hline 12 & 50 & Iso-04 & 3.91 & 2120 \\
\hline 12 & 50 & Iso-05 & 4.01 & 2124 \\
\hline $13 \mathrm{a}$ & 33 & AA-43-211-N & 2.27 & 2231 \\
\hline $13 \mathrm{a}$ & 33 & AA-43-212-N & 2.20 & 2235 \\
\hline $13 b$ & 60 & AA-43-208-N & 4.28 & 2213 \\
\hline 14 & 50 & Iso-08 & 5.11 & 2190 \\
\hline 14 & 50 & Iso-09 & 5.33 & 2181 \\
\hline 15 & 50 & Iso-10 & 6.93 & 2148 \\
\hline 15 & 50 & Iso-11 & 6.60 & 2138 \\
\hline
\end{tabular}

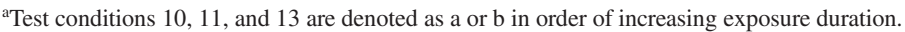




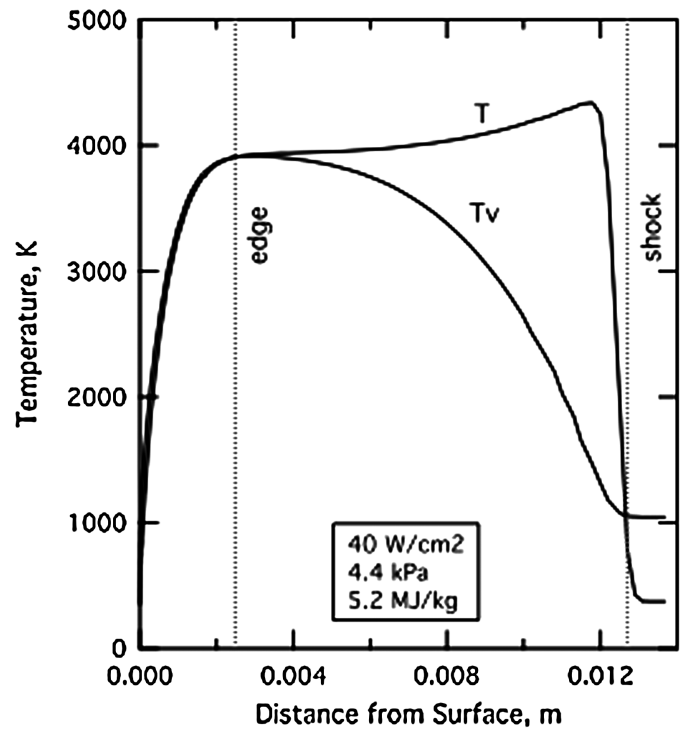

Fig. 4 Temperature profiles on stagnation line for test condition 1.

For each model in Table 2, the average recession rate may be calculated. Because charred PICA is carbon, the recession rate should depend on surface temperature and on the partial pressure of $\mathrm{O}_{2}$ or $\mathrm{O}$, depending on whether or not the dominant surface reaction is modeled as $\mathrm{O}+\mathrm{C}_{(s)} \rightarrow \mathrm{CO}$ or as $\mathrm{O}_{2}+2 \mathrm{C}_{(s)} \rightarrow 2 \mathrm{CO}$. The reaction rate depends quantitatively on temperatures and pressures at the ablating surface. Nevertheless, the average rate should approximately correlate with edge values of $\mathrm{O}$ and/or $\mathrm{O}_{2}$ (from Table $\underline{3}$ ). As seen in Figs. $\underline{8}$ and $\underline{9}$, the arcjet recession rate correlates well with atomic oxygen, but poorly with molecular oxygen. This result supports the first reaction model, rather than the second, and is consistent with the recommendations of Park [15].

\section{Material Response Analyses}

The integration between DPLR and FIAT is based on an uncoupled approach. The DPLR solutions assume steady flow and axial symmetry with a fully catalytic, cold-wall boundary condition at the model's surface. At the stagnation point, the recovery enthalpy and the unblown heat transfer coefficient are calculated from the DPLR solution, and then these parameters and pressure are passed as boundary conditions to FIAT. Surface thermochemical interactions and blowing effects are incorporated in the material-response code by use of ablation tables, a surface energy balance with heat transfer coefficient, and a blowing reduction parameter of $1 / 2$ for laminar flow. Further details on this coupling methodology may be found in $[\underline{6}, 13]$.

For all test conditions, FIAT calculations were performed using the nominal aerothermal environment, and also with a $\pm 10 \%$ scaling factor applied to the heating. This factor is considered to be the minimum uncertainty of the arcjet environment. As an example, Fig. 10 presents the predicted recession histories for these three heating levels for test condition 15 at $183 \mathrm{~W} / \mathrm{cm}^{2}$. The standard PICAv3.3 equilibrium ablation model was used. In all recession plots, the green, red, and blue curves are the FIAT predictions for $90 \%, 100 \%$, and $110 \%$ of nominal heating, respectively, and the

Table 3 Boundary-layer edge quantities from DPLR solutions-

\begin{tabular}{ccccccccc}
\hline \hline Test condition & $T, \mathrm{~K}$ & $T_{V}, \mathrm{~K}$ & \multicolumn{7}{c}{ Species mass fraction } \\
& & & $\mathrm{N}_{2}$ & $\mathrm{O}_{2}$ & $\mathrm{NO}$ & $\mathrm{N}$ & $\mathrm{O}$ & $\mathrm{Ar}$ \\
\hline 1 & 3906 & 3906 & 0.66245 & 0.14309 & 0.05126 & 0.00008 & 0.03812 & 0.10500 \\
2 & 6517 & 6359 & 0.55458 & 0.00172 & 0.02627 & 0.04016 & 0.16867 & 0.20860 \\
3 & 4069 & 4077 & 0.66551 & 0.13202 & 0.05507 & 0.00015 & 0.04865 & 0.09860 \\
4 & 7049 & 4957 & 0.56723 & 0.00187 & 0.02106 & 0.02994 & 0.17130 & 0.20860 \\
5 & 4356 & 4370 & 0.67833 & 0.11076 & 0.06740 & 0.00037 & 0.06904 & 0.07410 \\
6 & 3619 & 3623 & 0.62919 & 0.14251 & 0.04302 & 0.00004 & 0.03180 & 0.15344 \\
7 & 8007 & 6640 & 0.44065 & 0.00056 & 0.01579 & 0.11496 & 0.16204 & 0.26600 \\
8 & 3963 & 3968 & 0.65025 & 0.09732 & 0.06316 & 0.00021 & 0.07556 & 0.11350 \\
9 & 3935 & 3939 & 0.66784 & 0.09079 & 0.06936 & 0.00023 & 0.08502 & 0.08676 \\
10 & 7712 & 7743 & 0.49626 & 0.00043 & 0.01387 & 0.13142 & 0.18482 & 0.17320 \\
11 & 5088 & 5100 & 0.59406 & 0.00621 & 0.03212 & 0.00778 & 0.16404 & 0.19579 \\
12 & 6598 & 6757 & 0.58818 & 0.00060 & 0.01608 & 0.09077 & 0.19936 & 0.10500 \\
13 & 7384 & 7662 & 0.51771 & 0.00033 & 0.01212 & 0.14392 & 0.19593 & 0.13000 \\
14 & 5366 & 5382 & 0.59978 & 0.00297 & 0.02486 & 0.01572 & 0.17428 & 0.18240 \\
15 & 4737 & 4743 & 0.66347 & 0.01030 & 0.03863 & 0.00450 & 0.17749 & 0.10560 \\
\hline
\end{tabular}

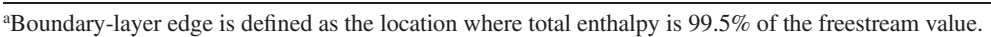

Table 4 Estimated equilibrium quantities at boundary-layer edge

\begin{tabular}{ccccccccc}
\hline \hline Test condition & Pressure, $\mathrm{Pa}$ & $\sqrt{T T_{V}}, \mathrm{~K}$ & \multicolumn{6}{c}{ Species mass fraction (from CEA) } \\
& & & $\mathrm{N}_{2}$ & $\mathrm{O}_{2}$ & $\mathrm{NO}$ & $\mathrm{N}$ & $\mathrm{O}$ & $\mathrm{Ar}$ \\
\hline 1 & 4395 & 3906 & 0.67764 & 0.00353 & 0.01334 & 0.00259 & 0.19789 & 0.10500 \\
2 & 1592 & 6437 & 0.05483 & 0.00000 & 0.00023 & 0.55207 & 0.18427 & 0.20860 \\
3 & 4918 & 4073 & 0.68138 & 0.00213 & 0.01163 & 0.00455 & 0.20170 & 0.09860 \\
4 & 1536 & 5911 & 0.17875 & 0.00000 & 0.00055 & 0.42800 & 0.18410 & 0.20860 \\
5 & 8887 & 4363 & 0.69580 & 0.00147 & 0.01164 & 0.00893 & 0.20806 & 0.07410 \\
6 & 13,381 & 3621 & 0.63600 & 0.02488 & 0.02758 & 0.00043 & 0.15767 & 0.15344 \\
7 & 2245 & 7292 & 0.00885 & 0.00000 & 0.00007 & 0.55410 & 0.17099 & 0.26600 \\
8 & 20,834 & 3966 & 0.66693 & 0.01135 & 0.02473 & 0.00147 & 0.18203 & 0.11350 \\
9 & 30,908 & 3937 & 0.68489 & 0.01801 & 0.03096 & 0.00110 & 0.17828 & 0.08676 \\
10 & 3797 & 7727 & 0.00698 & 0.00000 & 0.00007 & 0.62714 & 0.19261 & 0.17320 \\
11 & 13,404 & 5094 & 0.56915 & 0.00023 & 0.00590 & 0.04493 & 0.18400 & 0.19579 \\
12 & 6751 & 6677 & 0.12048 & 0.00001 & 0.00068 & 0.56566 & 0.20817 & 0.10500 \\
13 & 4946 & 7522 & 0.01475 & 0.00000 & 0.00014 & 0.65248 & 0.20264 & 0.13000 \\
14 & 13,951 & 5374 & 0.54466 & 0.00013 & 0.00479 & 0.08021 & 0.18782 & 0.18240 \\
15 & 26,672 & 4740 & 0.66524 & 0.00133 & 0.01314 & 0.01463 & 0.20006 & 0.10560 \\
\hline \hline
\end{tabular}




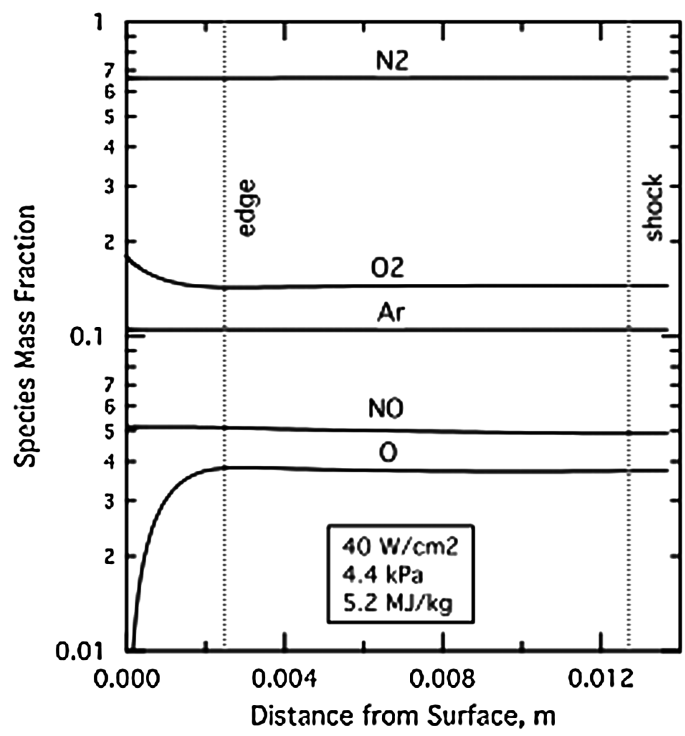

Fig. 5 Species mass fraction profiles on stagnation line for test condition 1. Similar results are obtained for test conditions 3 and 6.

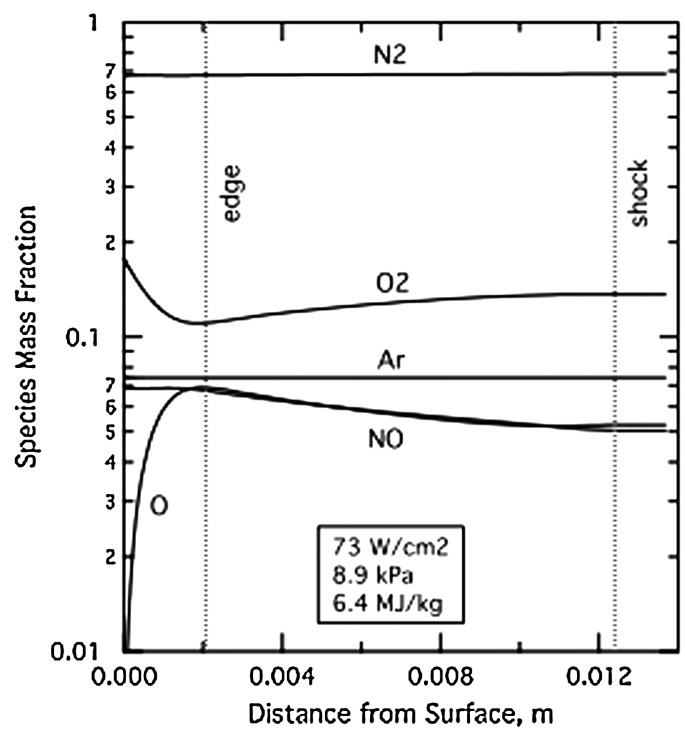

Fig. 6 Species mass fraction profiles on stagnation line for test condition 5. Similar results are obtained for test conditions 8 and 9.

black circles are measured data points with uncertainty bars of $\pm 0.5 \mathrm{~mm}$. The range of recession that results from the environmental uncertainty is shaded yellow. For this example, the two data points fall within the yellow-shaded region, and the ablation model is not assigned an error.

If a data point falls outside the range of predictions, then a recession-prediction error may be defined as

$$
E=\frac{\left(\Delta S_{\text {measured }}-\Delta S_{\text {FIAT }}\right)}{\left(\Delta S_{\text {measured }}\right)}
$$

where the closest FIAT result is used in the formula. In previous work, the recession-prediction error was less than $10 \%$ except for a few tests conducted at low pressure and/or heat flux. The possible influence of nonequilibrium effects for these two regimes is examined in the next two subsections.

\section{A. Nonequilibrium Effects at Low Pressure}

Predictions and data for test condition 7 at $107 \mathrm{~W} / \mathrm{cm}^{2}$ and $2.3 \mathrm{kPa}$ are shown in Fig. 11. In this case, although the data uncertainty bars intersect the yellow region, FIAT underpredicts the

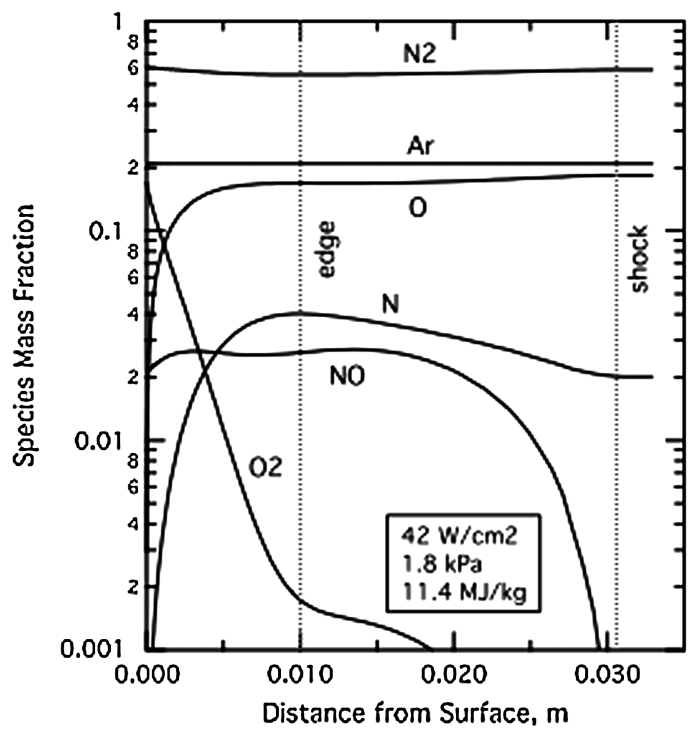

Fig. 7 Species mass fraction profiles on stagnation line for test condition 2. Similar results are obtained for test conditions 4 , 7 , and 10-15.

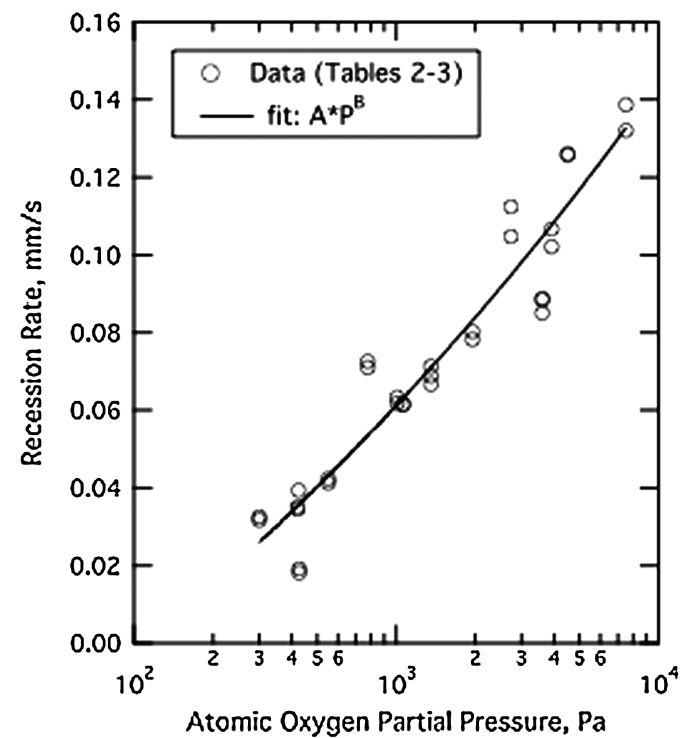

Fig. 8 Good correlation of recession rate with partial pressure of atomic oxygen.

actual data points. The measured recession was about $2.3 \mathrm{~mm}$, whereas FIAT predicts a recession range of 1.61-2.04 mm. The recession-prediction error is $12.7 \%$, which was the largest disagreement reported in [6].

Underprediction of the recession data was also seen in the three other tests conducted at pressure below $7 \mathrm{kPa}$ and heat flux above $100 \mathrm{~W} / \mathrm{cm}^{2}$ (test conditions 10, 12, and 13). It is unusual for carbon recession to exceed the predictions of an equilibrium model. At first, it was suspected that the measured recession could exceed the equilibrium prediction if, owing to the low pressure, there is an excess of $\mathrm{O}$ near the surface. To investigate this possibility, equilibrium ablation tables were calculated without the species $\mathrm{O}_{2}$ and $\mathrm{CO}_{2}$. That is, only $\mathrm{O}$ and $\mathrm{CO}$ were allowed. However, the equilibrium ablation rate was unchanged, because at equilibrium the ablated carbon becomes $\mathrm{CO}$ regardless of the state of the oxygen.

Equilibrium ablation $B_{c}^{\prime}$ curves for this test condition are illustrated in Fig. 12. At very low $B_{g}^{\prime}$, the curves show a plateau corresponding to diffusion-limited oxidation of carbon to $\mathrm{CO}$. However, as $B_{g}^{\prime}$ is increased, the plateau is suppressed, because the oxygen reacts with the pyrolysis gas as well as with the solid carbon. 


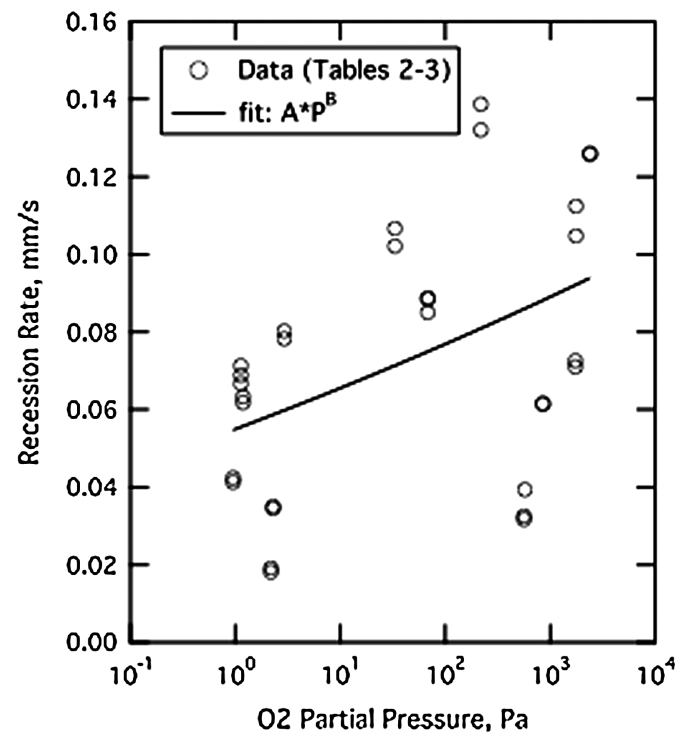

Fig. 9 Poor correlation of recession rate with partial pressure of molecular oxygen.

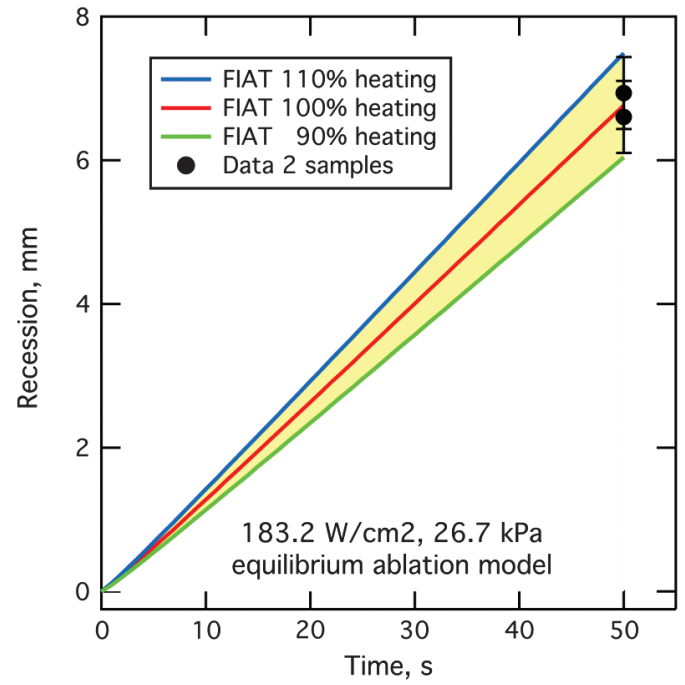

Fig. 10 Measured and predicted centerline recession for test condition 15 with environmental uncertainty. FIAT calculations assume full equilibrium ablation.

For this test condition, the surface state is near the location indicated by the red dot on Fig. 12, which represents approximately a $15 \%$ reduction from the diffusion-limited plateau at $B_{c}^{\prime}=0.129$. Indistinguishable curves are obtained whether the oxygen is modeled as an atomic or a molecular species.

An alternative approach, which increases the predicted recession, is to assume the pyrolysis gas is "inert" at low pressure. That is, the pyrolysis gas is assumed not to equilibrate with the boundary-layer gas if the pressure is sufficiently low. Pyrolysis gas is a multicomponent hydrocarbon mixture that may react with oxygen in the flowfield by a number of two- and three-body reactions. These homogeneous reactions have rates that are second or third order in pressure. At sufficiently low pressure, it is plausible that these reactions may become slow compared with the heterogeneous reaction for oxidation of solid carbon that is first order in pressure.

To investigate this alternative, new ablation tables were created by modeling the pyrolysis gas as one set of equilibrating species, and the test stream (air-argon) plus $\mathrm{C}_{(s)}$ and $\mathrm{CO}$ as a second set of equilibrating species. The modified ablation tables, depicted in Fig. 13, do not exhibit a suppression of the $B_{c}^{\prime}$ plateau regardless of the pyrolysis-gas blowing rate. Therefore the dimensionless ablation

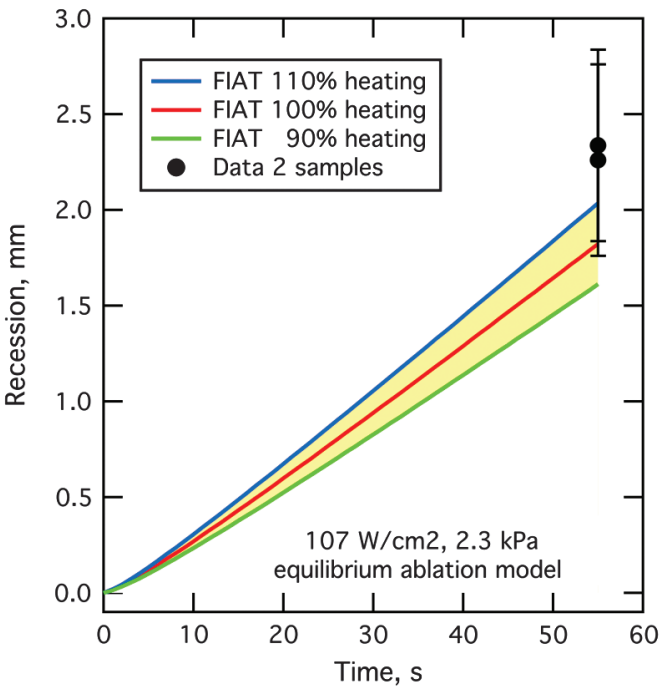

Fig. 11 Measured and predicted centerline recession for test condition 7 with environmental uncertainty. FIAT calculations assume full equilibrium ablation.

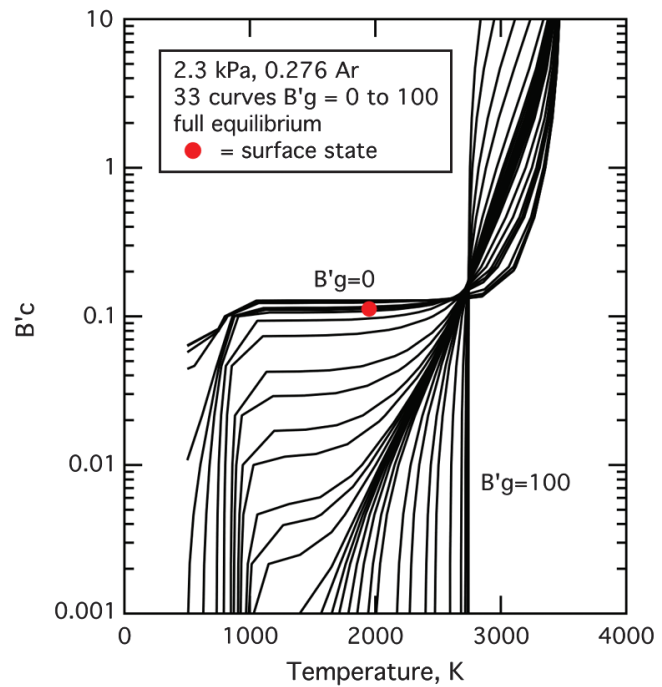

Fig. 12 Dimensionless ablation rate for test condition 7 assuming full equilibrium.

rate is 0.129 unless the temperature is sufficiently high to sublime carbon. Nevertheless, the pyrolysis gas flux still participates in the blowing correction to the heat transfer coefficient, and the gas enthalpy at the surface is a function of $B_{g}^{\prime}$.

Revised predictions of the surface recession for the three heating levels are presented in Fig. 14. The axis scales are the same as those used in Fig. 11. The recession predictions of the inert-pyrolysis-gas model are greater than for that of the full-equilibrium model and the level of agreement has been improved.

Figure 15 shows predictions of the temperature history at five locations along the axis of the model. The calculations were performed using the nominal (unscaled) heat flux and both ablation models. The results are so similar that it would be very difficult to distinguish between these two models based on temperature data.

Predictions from the two ablation models for all 15 test environments are listed in Tables 5 and 6 . These predictions are compared with the surface temperature and recession data in Figs. 16 and 17, respectively. In these figures, the vertical colored bars show the range of the predicted quantity corresponding to the assumed environmental uncertainty of $\pm 10 \%$. The red and blue bars show the predictions of the full-equilibrium and inert-pyrolysis-gas models, respectively. (The figures also have green bars for a kinetic ablation 


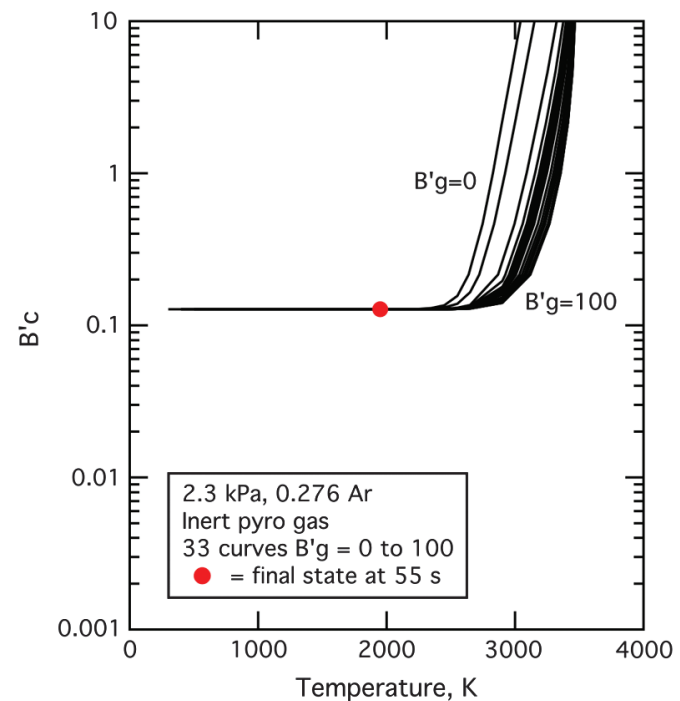

Fig. 13 Dimensionless ablation rate for test condition 7 assuming carbon equilibrium with inert pyrolysis gas.

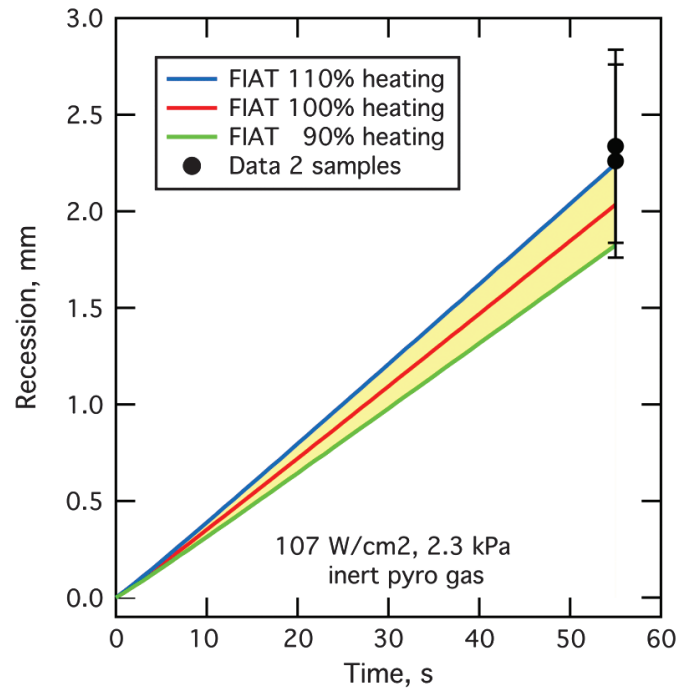

Fig. 14 Measured and predicted centerline recession for test condition 7 with environmental uncertainty. The FIAT calculations use the inert-pyrolysis-gas model.

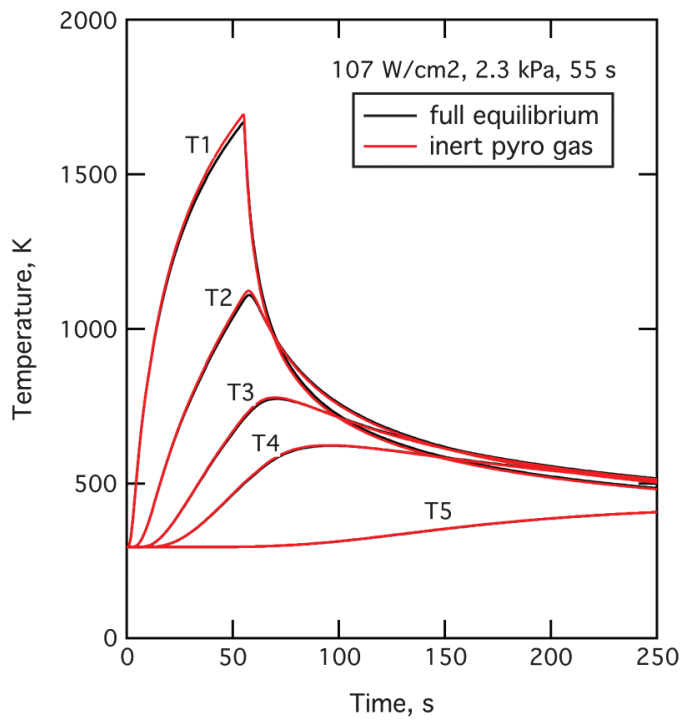

Fig. 15 Predicted in-depth temperatures at five depths along the axis for test condition 7 with nominal (unscaled) heating. model that will be discussed in the next subsection.) The predictions of the two equilibrium models (red and blue) are comparable; in most cases, the inert-pyrolysis-gas model gives just slightly greater recession and slightly lower surface temperature than the fullequilibrium model.

For surface temperature (Fig. 16), all predictions are within the uncertainty of the pyrometer data for all environments. The poorest agreement is test environment 9. For recession (Fig. 17), both equilibrium-based ablation models significantly overpredict the recession for most test conditions below $75 \mathrm{~W} / \mathrm{cm}^{2}$. Nonequilibrium modeling for low heat flux will be discussed in the next subsection. Considering only the tests above $100 \mathrm{~W} / \mathrm{cm}^{2}$, where surface equilibrium should be a good assumption, the inert-pyrolysis-gas model provides a slightly better match to the data for pressure environments below $7 \mathrm{kPa}$ (test conditions $7,10,12$, and 13), and the full-equilibrium model is slightly better for all cases above $13 \mathrm{kPa}$ (test conditions 8, 9, 11, 14, and 15). The recession figure uses a log axis so that the relative (fractional) error between predictions and data may be observed. Although the absolute error is largest for test condition 10 , the relative error is less than $10 \%$, which is comparable to the relative error from other test conditions.

The available data do not provide a pressure upper limit for applicability of the inert-pyrolysis-gas ablation model. This model should be used cautiously for pressure above the values considered in this work. Alternatively, a hybrid ablation model is suggested, in which the inert-pyrolysis-gas ablation tables are used for pressure up to $7 \mathrm{kPa}$, and full-equilibrium ablation tables are used down to $13 \mathrm{kPa}$. Some additional tables are needed to obtain a smooth transition for pressures between these two values. For these transitional tables, the composition of the air-argon set is adjusted to include various amounts of reactive elements from the pyrolysisgas set.

\section{B. Nonequilibrium Effects at Low Heat Flux}

Based on past experience with carbonaceous TPS materials, equilibrium ablation is a good assumption for surface temperature above $2000 \mathrm{~K}$, which corresponds to a heat flux of approximately $85 \mathrm{~W} / \mathrm{cm}^{2}$ for a high-emissivity material such as PICA. For surface temperature below $2000 \mathrm{~K}$, the ablation rate is typically below the calculated equilibrium rate, due to kinetic limitations to heterogeneous surface reactions. In Fig. 17, both equilibrium-based models (red and blue) overpredict the recession for test conditions 1 , 3,5 , and 6 at 40,45 , and $73 \mathrm{~W} / \mathrm{cm}^{2}$.

Interestingly, the equilibrium predictions are close to the data for test conditions 2 and 4 at 42 and $65 \mathrm{~W} / \mathrm{cm}^{2}$, respectively. For these two conditions, the oxygen is highly dissociated in the shock layer (Fig. 7), and the pressure is too low for atom recombination to be significant within the boundary layer. Therefore, a high level of atomic oxygen reaches the surface, and the reaction $\mathrm{O}+\mathrm{C}_{(s)} \rightarrow \mathrm{CO}$ approaches equilibrium even though the surface temperature is below $1800 \mathrm{~K}$. The equilibrium models provide a good estimate for $B_{c}^{\prime}$ despite their apparent inapplicability.

For the ablation of carbon in air-argon mixtures, three applicable heterogeneous reactions are oxidation, nitridation, and sublimation:

$$
\begin{gathered}
\mathrm{O}+\mathrm{C}_{(s)} \rightarrow \mathrm{CO} \\
\mathrm{N}+\mathrm{C}_{(s)} \rightarrow \mathrm{CN} \\
3 \mathrm{C}_{(s)} \rightarrow \mathrm{C}_{3}
\end{gathered}
$$

The forward rate for the oxidation reaction may be expressed as

$$
r_{f}=\eta p_{o} \sqrt{\frac{M_{o}}{2 \pi R T}}
$$

with a reaction probability from Park [15]:

$$
\eta=0.63 \exp (-1160 / T)
$$


Table 5 Predictions of the equilibrium ablation model

\begin{tabular}{ccrrrr}
\hline \hline Test condition & Exposure time, $\mathrm{s}$ & \multicolumn{2}{c}{ Recession, mm } & \multicolumn{2}{c}{ Maximum surface temperature, K } \\
\cline { 3 - 6 } & & $90 \%$ heating & $110 \%$ heating & $90 \%$ heating & $110 \%$ heating \\
\hline 1 & 200 & 8.549 & 10.541 & 1544 & 1618 \\
2 & 200 & 3.376 & 4.215 & 1568 & 1649 \\
3 & 240 & 10.895 & 13.425 & 1593 & 1668 \\
4 & 200 & 5.455 & 6.780 & 1749 & 1836 \\
5 & 120 & 7.859 & 9.701 & 1772 & 1856 \\
6 & 120 & 10.222 & 12.585 & 1760 & 1840 \\
7 & 55 & 1.611 & 2.035 & 1956 & 2057 \\
8 & 80 & 8.681 & 10.708 & 1954 & 2043 \\
9 & 80 & 10.125 & 12.488 & 2023 & 2114 \\
$10 \mathrm{a}$ & 200 & 8.975 & 11.164 & 2125 & 2229 \\
$10 \mathrm{~b}$ & 400 & 18.292 & 22.730 & 2138 & 2253 \\
$11 \mathrm{a}$ & 33 & 2.939 & 3.662 & 2104 & 2206 \\
$11 \mathrm{~b}$ & 66 & 6.020 & 7.467 & 2119 & 2220 \\
12 & 50 & 3.127 & 3.916 & 2167 & 2275 \\
$13 \mathrm{a}$ & 33 & 1.658 & 2.097 & 2175 & 2286 \\
$13 \mathrm{~b}$ & 60 & 3.132 & 3.933 & 2191 & 2301 \\
14 & 50 & 4.795 & 5.962 & 2182 & 2286 \\
15 & 50 & 6.040 & 7.492 & 2197 & 2299 \\
\hline \hline
\end{tabular}

Table 6 Predictions of the inert-pyrolysis-gas ablation model

\begin{tabular}{crrrrr}
\hline \hline Test condition & Exposure time, $\mathrm{s}$ & \multicolumn{2}{c}{ Recession, mm } & \multicolumn{2}{c}{ Maximum surface temperature, K } \\
& & $90 \%$ heating & $110 \%$ heating & $90 \%$ heating & $110 \%$ heating \\
\hline 1 & 200 & 8.991 & 11.020 & 1538 & 1612 \\
2 & 200 & 3.757 & 4.620 & 1563 & 1644 \\
3 & 240 & 11.412 & 13.984 & 1587 & 1663 \\
4 & 200 & 5.884 & 7.225 & 1744 & 1832 \\
5 & 120 & 8.232 & 10.090 & 1767 & 1851 \\
6 & 120 & 10.627 & 13.015 & 1754 & 1834 \\
7 & 55 & 1.824 & 2.247 & 1949 & 2052 \\
8 & 80 & 8.994 & 11.017 & 1949 & 2038 \\
9 & 80 & 10.435 & 12.780 & 2019 & 2110 \\
$10 \mathrm{a}$ & 200 & 9.379 & 11.508 & 2122 & 2227 \\
$10 \mathrm{~b}$ & 400 & 18.885 & 23.181 & 2139 & 2254 \\
$11 \mathrm{a}$ & 33 & 3.104 & 3.810 & 2099 & 2202 \\
$11 \mathrm{~b}$ & 66 & 6.257 & 7.672 & 2116 & 2217 \\
12 & 50 & 3.317 & 4.077 & 2163 & 2272 \\
$13 \mathrm{a}$ & 33 & 1.812 & 2.232 & 2169 & 2282 \\
$13 \mathrm{~b}$ & 60 & 3.336 & 4.102 & 2187 & 2298 \\
14 & 50 & 4.984 & 6.113 & 2179 & 2284 \\
15 & 50 & 6.225 & 7.632 & 2194 & 2297 \\
\hline \hline
\end{tabular}

The effective reaction probability may vary depending on the chemical state and roughness of the ablating material, but expression (6) is a good starting point for analysis. For the test conditions in this study, the rates for nitridation and sublimation were found to be negligible in comparison with the rate for oxidation.

Ablation tables that include reaction kinetics may be generated using the MAT code. The tables contain an additional dimensionless

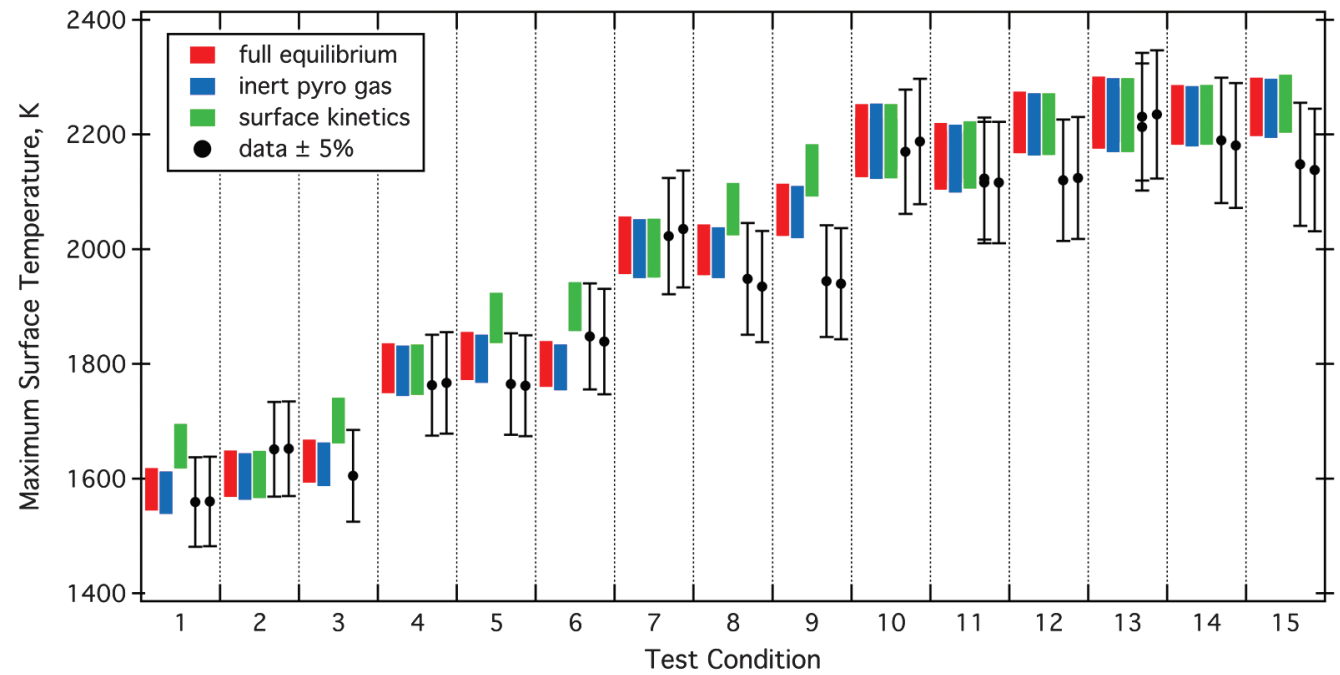

Fig. 16 Range of maximum temperature predictions from three ablation models (colored bars) compared with data (black points). 


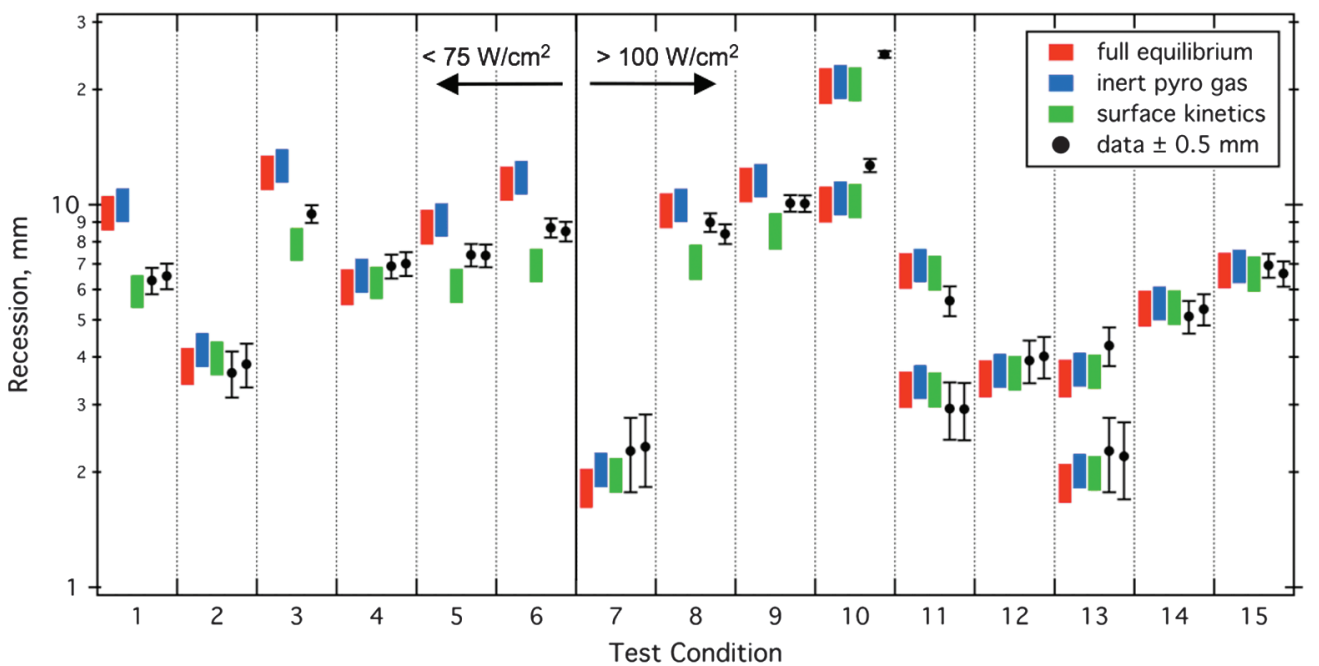

Fig. 17 Range of recession predictions from three ablation models (colored bars) compared with data (black points). Test conditions 10,11, and 13 have two exposure durations.

parameter that is the ratio of the forward reaction rate $r_{f}$ to the mass transfer coefficient $\rho_{e} u_{e} C_{M}$, where both quantities have units of mass flux. Typically the heat transfer coefficient $\rho_{e} u_{e} C_{H}$ is estimated from measured quantities and/or computational fluid dynamics solutions, and then $C_{M}=C_{H}$ is assumed unless additional information is available.

For pyrolyzing ablators, these kinetic ablation tables contain four independent parameters: pressure, $B_{c}^{\prime}, B_{g}^{\prime}$, and $\rho_{e} u_{e} C_{M}$. It is impractical to create and to interpolate tables with four or more independent variables. Furthermore, for the same material, different tables are needed for each atmospheric composition (i.e., argon mass fraction) to be analyzed. To circumvent these difficulties, the FIAT code was modified to enable calculation of the ablation rate without the intermediate step of table generation. This improved methodology is documented in [16].

For the full-equilibrium model, it is unclear how to properly implement the surface kinetics. If the pyrolysis gas is allowed to equilibrate with the edge gas, then most of the carbon in the pyrolysis gas is converted into $\mathrm{CO}$ and/or $\mathrm{CO}_{2}$, and only a small amount of oxygen is available to react with the solid carbon. In other words, the suppression of $B_{c}^{\prime}$ owing to pyrolysis, as seen in Fig. 12, always occurs in addition to kinetic limitations to surface reactions of any surplus oxygen. The net result is a large reduction in $B_{c}^{\prime}$. If the Park surface kinetics are combined with the full-equilibrium model, then the ablation rate is underpredicted by more than an order of magnitude for all test conditions below $100 \mathrm{~W} / \mathrm{cm}^{2}$.
For the inert-pyrolysis-gas model, the finite-rate reactions may be implemented in the subset of species that includes the test stream (air-argon) plus $\mathrm{C}_{(s)}$ and CO. Calculations were performed for all test environments using this combination of models. Also, for each condition, the edge fraction of atomic oxygen from Table $\underline{3}$ was specified as a boundary condition. This specification is required for two reasons: 1) the flowfields are not in chemical equilibrium, and 2) the primary source of atomic species $(\mathrm{O}$ and $\mathrm{N})$ is from the boundary-layer edge.

Temperature and recession predictions of the kinetic model are listed in Table 7 and shown as vertical green bars in Figs. 16 and 17, respectively. For the higher enthalpy cases (above $8.5 \mathrm{MJ} / \mathrm{kg}$, test conditions $2,4,7$, and 10-15), the three models give comparable results for both quantities. The temperature predictions are within the uncertainty of the pyrometer data but usually on the high side of the error bars. The recession predictions show both positive and negative errors compared with the data. The kinetic model appears to be as accurate as the full equilibrium model, even for the highest pressures (conditions 11,14, and 15) where some of the modeling assumptions may be questionable.

For the lower enthalpy cases (below $6.5 \mathrm{MJ} / \mathrm{kg}$, test conditions 1 , $3,5,6,8$, and 9), the results are inconclusive. The kinetic model predicts lower recession and higher temperature than the two equilibrium-based models. The surface temperature predictions (Fig. 16) of the kinetic model appear to be high, but within the error bars of the data except for test condition 9 . The recession predictions

Table 7 Predictions of the inert-pyrolysis-gas ablation model with surface kinetics

\begin{tabular}{cccccc}
\hline \hline Test condition & Exposure time, $\mathrm{s}$ & \multicolumn{2}{c}{ Recession, mm } & \multicolumn{2}{c}{ Maximum surface temperature, $\mathrm{K}$} \\
& & $90 \%$ heating & $110 \%$ heating & $90 \%$ heating & $110 \%$ heating \\
\hline 1 & 200 & 5.363 & 6.538 & 1617 & 1695 \\
2 & 200 & 3.576 & 4.390 & 1566 & 1648 \\
3 & 240 & 7.114 & 8.687 & 1661 & 1741 \\
4 & 200 & 5.669 & 6.887 & 1746 & 1834 \\
5 & 120 & 5.536 & 6.799 & 1836 & 1924 \\
6 & 120 & 6.263 & 7.664 & 1857 & 1942 \\
7 & 55 & 1.766 & 2.178 & 1950 & 2053 \\
8 & 80 & 6.348 & 7.870 & 2024 & 2115 \\
9 & 80 & 7.629 & 9.507 & 2092 & 2183 \\
$10 \mathrm{a}$ & 200 & 9.221 & 11.339 & 2123 & 2227 \\
$10 \mathrm{~b}$ & 400 & 18.580 & 22.857 & 2139 & 2253 \\
$11 \mathrm{a}$ & 33 & 2.946 & 3.643 & 2106 & 2207 \\
$11 \mathrm{~b}$ & 66 & 5.952 & 7.356 & 2123 & 2223 \\
12 & 50 & 3.263 & 4.023 & 2164 & 2272 \\
$13 \mathrm{a}$ & 33 & 1.787 & 2.204 & 2169 & 2282 \\
$13 \mathrm{~b}$ & 60 & 3.293 & 4.054 & 2187 & 2298 \\
14 & 50 & 4.839 & 5.974 & 2182 & 2286 \\
15 & 50 & 5.913 & 7.330 & 2203 & 2304 \\
\hline \hline
\end{tabular}




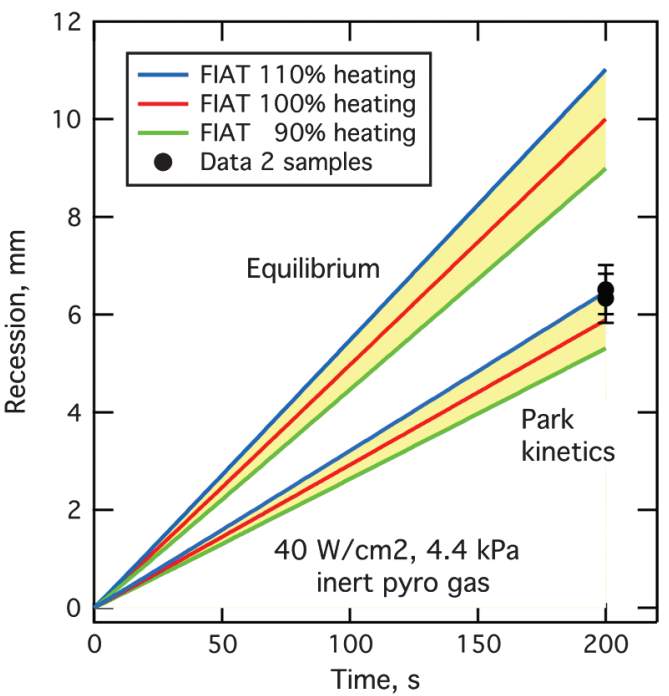

Fig. 18 Measured and predicted centerline recession for test condition 1 with environmental uncertainty. FIAT calculations use the inert-pyrolysis-gas model with either surface equilibrium or Park kinetics.

(Fig. 17) of the kinetic model have comparable or better accuracy than those of the equilibrium models, except for one sample (Model ID Iso-14) tested at condition 8.

Figure 18 presents the predicted surface ablation for three heating levels for test condition 1 using the two inert-pyrolysis-gas models. The equilibrium model overpredicts the data, whereas the kinetic model agrees with the data. For some low-enthalpy cases, the kinetic model underpredicts the data. One such example is provided in Fig. 19 for test condition 3. The kinetic model has an error of $8 \%$, whereas the equilibrium model has an error of $-21 \%$.

Because the kinetic model underpredicted some of the data, we investigated the possibility that an increase in the reaction rates would improve the results. However, setting $\eta=1$ in the oxidation reaction [Eq. (6)] resulted in only a small increase in the calculated recession. In these environments, the kinetic ablation rate is limited mostly by the amount of atomic oxygen, which is a boundary condition obtained from the DPLR solutions.

Based on the preceding discussion, the inert-pyrolysis-gas model with surface kinetics is recommended for heat flux or surface temperature below $85 \mathrm{~W} / \mathrm{cm}^{2}$ or $2000 \mathrm{~K}$, respectively. This model

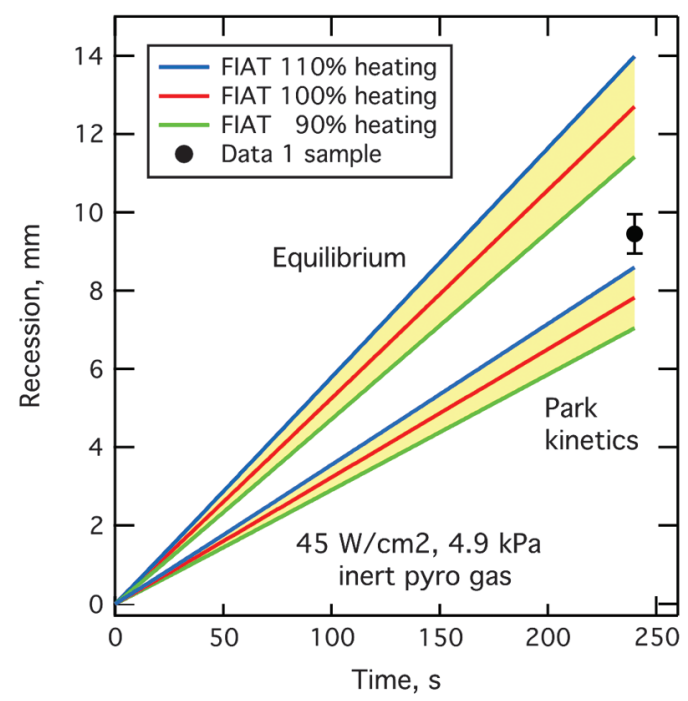

Fig. 19 Measured and predicted centerline recession for test condition 3 with environmental uncertainty. FIAT calculations use the inert-pyrolysis-gas model with either surface equilibrium or Park kinetics. may be used for surface temperature up to perhaps $2250 \mathrm{~K}$ with recession errors comparable to those of equilibrium-based ablation models. However, in some low-enthalpy flows (specifically, test conditions 8 and 9) the kinetics model underpredicted the recession. Therefore, from a project perspective, the equilibrium-based models may be considered more conservative, in the sense that they overpredicted the recession in the same environments. The equilibrium models are applicable for surface temperature as low as $2000 \mathrm{~K}$, which is a traditional value from past experience.

Results for test conditions 2 and 4 suggest that the equilibrium models also may be used below $2000 \mathrm{~K}$, if the edge oxygen is dissociated and the pressure is sufficiently low $(<2 \mathrm{kPa})$ to prevent reactions of atomic oxygen in the boundary layer. This type of environment often occurs during the initial part of a hypersonic entry trajectory.

\section{Conclusions}

Data were presented from stagnation arcjet tests of iso-q- and flatface-shaped Phenolic Impregnated Carbon Ablator (PICA) models. Thirty-one models were tested in the Aerodynamic Heating Facility at NASA Ames Research Center at 15 test conditions with stagnation-point heat fluxes from 40 to $183 \mathrm{~W} / \mathrm{cm}^{2}$ and pressures from 1.6 to $31.6 \mathrm{kPa}$. The surface temperature was estimated using multiple pyrometers, and the posttest recession was measured. Two modifications to the standard PICAv3.3 equilibrium ablation model were developed to address nonequilibrium effects that occur at low pressure and at low temperature. Predictions of the standard and the modified ablation models were compared with the test data.

For heat flux above $85 \mathrm{~W} / \mathrm{cm}^{2}$ (surface temperature above $2000 \mathrm{~K}$ ), two equilibrium-based models provided comparably good agreement with the recession data. The inert-pyrolysis-gas model was slightly better for stagnation pressure below $7 \mathrm{kPa}$, and the standard full-equilibrium model (PICAv3.3) was slightly better for pressure above $13 \mathrm{kPa}$.

For heat flux below $85 \mathrm{~W} / \mathrm{cm}^{2}$ (surface temperature below $2000 \mathrm{~K}$ ), in most cases, the equilibrium-based models overpredicted the surface recession. To obtain a good match to the recession data, a simple surface kinetics model was implemented with the inertpyrolysis-gas assumption, and the atomic oxygen fraction at the boundary-layer edge was specified. This specification was critical, because otherwise the kinetics model underpredicted the recession in all environments.

\section{Acknowledgments}

This work was supported in part by the NASA Orion Insight/ Oversight Project and through contract NNA04BG25C to ELORET Corporation. We acknowledge the NASA Strategic Capabilities Assets Program for their critical financial support of the arcjet operational capability at Ames Research Center. The authors greatly appreciate the assistance of P. Agrawal, D. Driver, M. Olson, and K. Skokova for arcjet test data.

\section{References}

[1] Tran, H., Johnson, C, Rasky, D., Hui, F., Chen, Y.-K., and Hsu, M., "Phenolic Impregnated Carbon Ablators (PICA) for Discovery Class Missions," AIAA Paper 96-1911, June 1996.

[2] Willcockson, W. H., "Stardust Sample Return Capsule Design Experience," Journal of Spacecraft and Rockets, Vol. 36, No. 3, 1999, pp. $470-474$. doi: $10.2514 / 2.3468$

[3] Beck, R., Driver, D., Wright, M., Laub, B., Hwang, H., Slimko, E., Edquist, K., Sepka, S., Wilcockson, W., and Thames, T., "Development of the Mars Science Laboratory Heatshield Thermal Protection System," AIAA Paper 2009-4229, June 2009.

[4] Scott, A., Berry, S. A., Horvath, T. J., Lillard, R. P., Kirk, B. S., and Cassady, A. M., "Aerothermal Testing for Project Orion Crew Exploration Vehicle," AIAA Paper 2009-3842, June 2009.

[5] Chen, Y.-K., and Milos, F. S., "Ablation and Thermal Analysis Program for Spacecraft Heatshield Analysis," Journal of Spacecraft and Rockets, Vol. 36, No. 3, 1999, pp. 475-483. 
doi: $10.2514 / 2.3469$

[6] Milos, F. S., and Chen, Y.-K., "Ablation and Thermal Response Property Model Validation for Phenolic Impregnated Carbon Ablator," Journal of Spacecraft and Rockets, Vol. 47, No. 5, 2010, pp. 786-805. doi: $10.2514 / 1.42949$

[7] Balter-Peterson, A., Nichols, F., Mifsud, B., and Love, W., "Arc Jet Testing in NASA Ames Research Center Thermophysics Facilities," AIAA Paper 1992-5041, Dec. 1992.

[8] Anon., "Standard Test Method for Measuring Heat-Transfer Rate Using a Thermal Capacitance (Slug) Calorimeter," ASTM International, West Conshohocken, PA, Standard E-457-08, 2008.

[9] Milos, F. S., and Chen, Y.-K., "Comprehensive Model for Multicomponent Ablation Thermochemistry," AIAA Paper 97-0141, Jan. 1997.

[10] Wright, M. J., Candler, G. V., and Bose, D., "Data-Parallel Line Relaxation Method for the Navier-Stokes Equations," AIAA Journal, Vol. 36, No. 9, 1998, pp 1603-1609. doi: $10.2514 / 2.586$

[11] Park, C., Nonequilibrium Hypersonic Aerothermodynamics, Wiley, New York, 1990, Chapter 4.

[12] Park, C., "Assessment of a Two-Temperature Kinetic Model for Dissociating and Weakly Ionizing Nitrogen," Journal of Thermophy- sics and Heat Transfer, Vol. 2, No. 1, 1988, pp 8-16. doi: $10.2514 / 3.55$

[13] Gökçen, T., Chen, Y.-K., Skokova, K., and Milos, F. S., "Computational Analysis of Arc-Jet Stagnation Tests Including Ablation and Shape Change," Journal of Thermophysics and Heat Transfer, Vol. 24, No. 4, 2010, pp. 694-707. doi:10.2514/1.46199

[14] McBride, B. J., and Gordon, S., "Computer Program for Calculation of Complex Chemical Equilibrium Compositions and Applications, Part II: User's Manual and Program Description,” NASA RP-1311, June 1996.

[15] Park, C., "Numerical Implementation of Surface Catalysis, Reaction, and Sublimation," Experiment, Modeling and Simulation of GasSurface Interactions for Reactive Flows in Hypersonic Flights, RTOEN-AVT-142, Neuilly-sur-Seine, France, July 2007, pp. 16-1-16-20.

[16] Milos, F. S., and Chen, Y.-K., "Ablation, Thermal Response, and Chemistry Program for Analysis of Thermal Protection Systems," AIAA Paper 2010-4663, June 2010. 